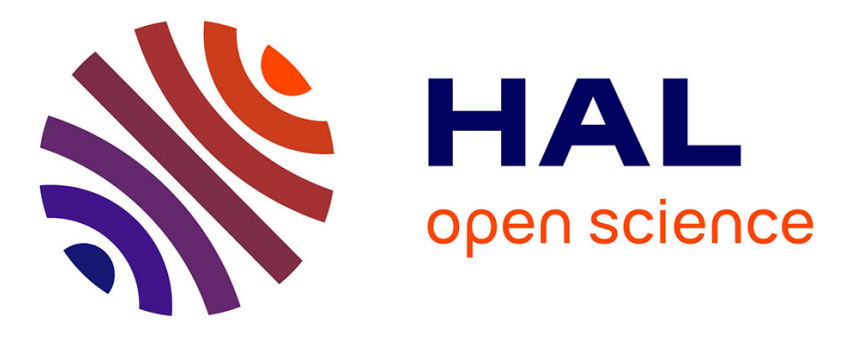

\title{
Extra hydrogen bonding interactions by peripheral indole groups stabilize benzene-1,3,5-tricarboxamide helical assemblies
}

Gaëtan Basuyaux, Alaric Desmarchelier, Geoffrey Gontard, Nicolas

Vanthuyne, Jamal Moussa, Hani Amouri, Matthieu Raynal, Laurent Bouteiller

\section{To cite this version:}

Gaëtan Basuyaux, Alaric Desmarchelier, Geoffrey Gontard, Nicolas Vanthuyne, Jamal Moussa, et al.. Extra hydrogen bonding interactions by peripheral indole groups stabilize benzene1,3,5-tricarboxamide helical assemblies. Chemical Communications, 2019, 55 (59), pp.8548-8551. 10.1039/C9CC03906F . hal-02304426

\section{HAL Id: hal-02304426 \\ https: / hal.sorbonne-universite.fr/hal-02304426}

Submitted on 3 Oct 2019

HAL is a multi-disciplinary open access archive for the deposit and dissemination of scientific research documents, whether they are published or not. The documents may come from teaching and research institutions in France or abroad, or from public or private research centers.
L'archive ouverte pluridisciplinaire HAL, est destinée au dépôt et à la diffusion de documents scientifiques de niveau recherche, publiés ou non, émanant des établissements d'enseignement et de recherche français ou étrangers, des laboratoires publics ou privés. 
Journal Name

COMMUNICATION

Received 00th January 20xx, Accepted 00th January 20xx

DOI: $10.1039 / \times 0 \times x 00000 x$

\section{Extra hydrogen bonding interactions by peripheral indole groups stabilize benzene-1,3,5-tricarboxamide helical assemblies}

\author{
Gaëtan Basuyaux, a Alaric Desmarchelier, ${ }^{a}$ Geoffrey Gontard, ${ }^{a}$ Nicolas Vanthuyne, ${ }^{\text {b }}$ Jamal
} Moussa, ${ }^{\text {a }}$ Hani Amouri, ${ }^{a}$ Matthieu Raynal, ${ }^{\text {a }}$ and Laurent Bouteiller ${ }^{a}$

\section{www.rsc.org/}

Benzene-1,3,5-tricarboxamide monomers derived from alkyl esters of tryptophan (BTA Trp) self-assemble into helices with an inner threefold hydrogen bond network surrounded by a second network involving the indole $\mathrm{N}-\mathrm{H}$ groups. As a consequence of this extra stabilization of its helical assemblies, BTA Trp forms more viscous solutions than a range of ester and alkyl BTAs.

The bottom-up assembly of small synthetic molecules provides an efficient strategy for the construction of artificial helices and their implementation in chirality-based applications. ${ }^{1}$ In this context benzene-1,3,5-tricarboxamide (BTA $)^{2}$ molecules constitute an iconic class of monomers given their ability to predictably form helical assemblies with a preferred handedness, and their utility as asymmetric catalysts, ${ }^{3}$ circularly-polarized light emitters ${ }^{4}$ and chiral templates. ${ }^{5}$ Stacks of BTA molecules in the form of a threefold hydrogen bonded helix connecting the amide units has been characterized in the crystalline state ${ }^{6}$ in the liquid-crystalline state, $^{7}$ in gel $^{8}$ and in solution. ${ }^{2 a, 9}$ An important challenge for imparting these supramolecular polymers with further functionality is to introduce functional groups in their side chains without destabilizing the helices. Comparatively to BTAs bearing alkyl chains (alkyl BTAs), a significant destabilization of the assemblies has been reported for BTAs endowed with short ethylene glycol chains ${ }^{10}$ or derived from $\alpha$-amino esters (ester BTAs). ${ }^{11}$

In the case of ester BTAs, the hydrogen bond competing nature of the ester group is reflected by the possible formation of a dimeric structure in which the $\mathrm{N}-\mathrm{H}$ moieties are bound to the ester $\mathrm{C}=\mathrm{O}$, instead of amide $\mathrm{C}=\mathrm{O}$ in the case of helical BTA stacks. ${ }^{11 \mathrm{c}-\mathrm{e}}$ Moreover, the nature of the substituent attached to the aminoester $\alpha$-carbon significantly influences the assembly properties of ester BTAs. Previous studies revealed that stereoelectronic ${ }^{11 d}$ and conformational effects ${ }^{11 e}$ can strongly shift the assembly of ester BTAs from dimers to stacks. Also, weak non-covalent interactions involving the side chains of the BTAs derived from Lphenylalanine $e^{11 a, 11 c, 11 e, 11 f}$ or L-methionine ${ }^{6 e, 11 c, 11 e}$ help stabilize the helical assemblies in apolar solvents. Nevertheless, these helices are less stable, by at least one order of magnitude, than alkyl BTAs. $^{11 e}$

\footnotetext{
a. Sorbonne Université CNRS, Institut Parisien de Chimie Moléculaire, 4 Place Jussieu, 75005 Paris (France) e-mail: jamal.moussa@sorbonne-universite.fr matthieu.raynal@sorbonne-universite.fr.

b. Aix Marseille Université, Centrale Marseille, CNRS, iSm2, UMR 7313, 13397 Marseille Cedex 20 (France)

$\dagger$ Electronic Supplementary Information (ESI) available: Chart S1, general procedures, supplementary figures (Figs. S1-S9), Table S1, and synthetic procedures. See DOI: 10.1039/x0xx00000x
}

Much effort has been devoted towards the stabilization of $\alpha$-helical peptides and mimetics ${ }^{12}$ and of the collagen triple helix, ${ }^{13}$ which can be achieved by chemical mutation of a particular amino-acid, amongst other possible strategies. Moreover, the helical conformation of synthetic covalent polymers such as poly(isocyanide) $s^{14}$ and poly(acetylene) $s^{15}$ can be stabilized by means of hydrogen bonding interactions involving the polymer side chains. Such a toolbox for the stabilization of artificial supramolecular helices by strong interactions between peripheral groups is currently lacking. ${ }^{16}$ Taking into consideration the possible array of interactions involving the indole moiety, ${ }^{17}$ we became interested in the self-assembly properties of BTA monomers derived from tryptophan alkyl esters (BTA Trp). We report herein that BTA Trp monomers, thanks to additional hydrogen bonding interactions provided by the indole groups, self-assemble into remarkably stable supramolecular helices in apolar solvents.
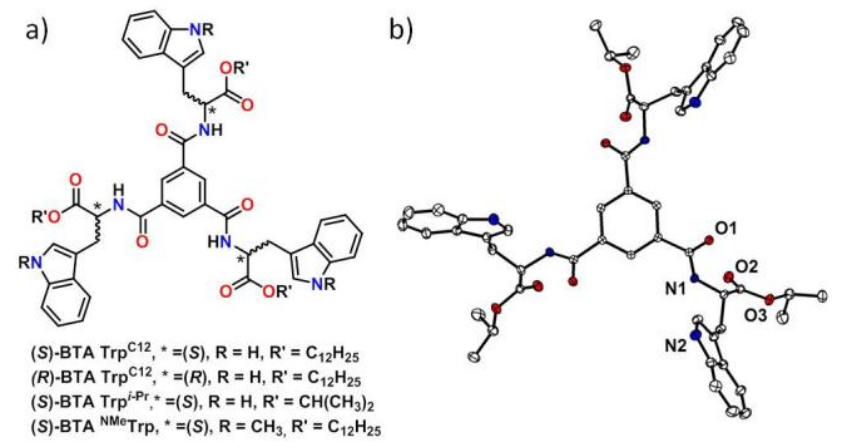

Chart 1 (a) Chemical structures of the BTA monomers investigated in this study. (b) ORTEP representation of an isolated molecule of (S)-BTA $\operatorname{Trp}^{i-\mathrm{Pr}}$ together with heteroatom labels.

BTA Trp monomers (Chart 1) with dodecyl (BTA Trp ${ }^{\text {C12 }}$ ) or isopropyl (BTA $\operatorname{Trp}^{i-\mathrm{Pr}}$ ) ester chains have been prepared via conventional synthetic procedures and have been isolated in pure form according to ${ }^{1} \mathrm{H}$ NMR, ${ }^{13} \mathrm{C}$ NMR, High-Resolution Mass Spectrometry and Fourier-Transform Infrared (FT-IR) analyses (ESI + ). Chiral HPLC analyses certify that both (S)-BTA $\operatorname{Trp}^{\text {C12 }}$ and (S)-BTA $\operatorname{Trp}^{i \text {-Pr }}$ are enantiopure (de> 99\%, ee> 99\%). (S)-BTA ${ }^{\mathrm{NMe}}$ Trp has been synthesized from $\mathrm{N}$-methyl $(S)$-tryptophan with the purpose of determining the influence of the indole $\mathrm{N}-\mathrm{H}$ group on the selfassembly properties of BTA Trp monomers.

Crystals of (S)-BTA $\operatorname{Trp}^{i-\mathrm{Pr}}$ have been obtained by cooling of a concentrated solution in $\mathrm{CH}_{3} \mathrm{CN}$. (S)-BTA $\mathrm{Trp}^{i-\mathrm{Pr}}$ crystallizes in the hexagonal $P G_{3}$ space group, a view of the isolated molecule is shown in Chart 1. 


\section{COMMUNICATION}

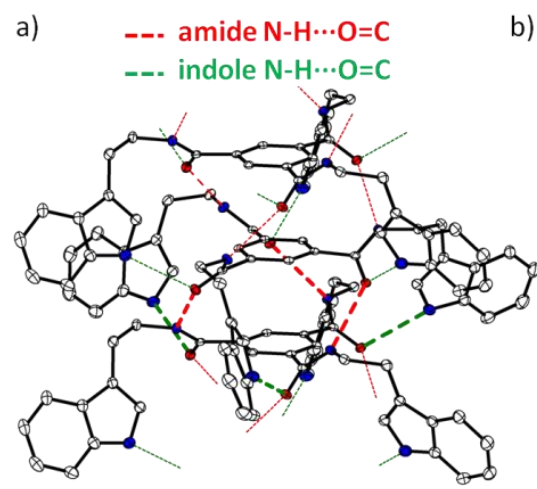

b)

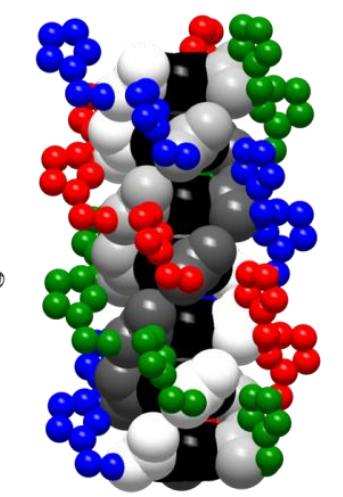

Fig. 1 X-ray structure of (S)-BTA Trp ${ }^{i-\text { Pr }}$. (a) ORTEP representation of a trimer of (S)-BTA $\operatorname{Trp}^{i-\text { Pr }}$ with the two types of hydrogen bonds present in the helical polymer shown in green (indole/amide) and red (amide/amide). The ester side chains $\left(\mathrm{CO}_{2} i-\mathrm{Pr}\right)$ and hydrogen atoms are omitted for clarity. The six hydrogen bonds connecting the lower monomer pair are shown with a thicker dotted line. Selected distances $(\AA)$ : N1 $\cdots 01$ :

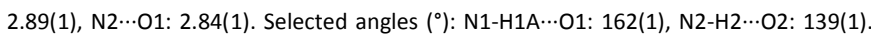
(b) Diagram of a hexamer of (S)-BTA Trp ${ }^{i-\text { Pr }}$ highlighting the inner helical threefold hydrogen bond network (O, C, NH helical strands shown with different shades of grey, BTA ring in black) surrounded by the second helical network involving the indole moiety $\left(\mathrm{CH}, \mathrm{CH}_{2}, \mathrm{~N}\right.$ ring corresponding to different strands are shown in blue, red and green). The amide $\mathrm{C}=\mathrm{O}$ are common to both hydrogen bond networks.

Examining the packing arrangement in the crystal shows that (S)-BTA $\operatorname{Trp}^{i-P r}$ molecules stack upon each other and form supramolecular helices by means of a double hydrogen bond network: (i) an inner helical network involving the amide functions only (see the red dotted lines in Fig. 1a and the strands colored with different shades of grey in Fig. 1b) similar to the one observed in the crystalline structures of other alkyl

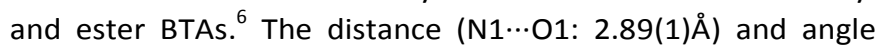

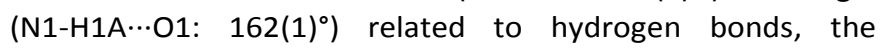
aromatic-amide dihedral angle $\left(40(1)^{\circ}\right)$ and the distance between the central arenes (3.54(1) $\AA$ ) match those found for BTAs reported in the literature (see compiled structural data in Table S1). The refinement of the Flack $x$ parameter, equal to $0.00(17)$, ascertains the absolute configuration of the structure, i.e. (S)-BTA $\operatorname{Trp}^{i-\operatorname{Pr}}$ assembles into right-handed helices which is in agreement with the handedness of helices found for other ester BTAs having (S)-configuration. ${ }^{6 d, 6 e}$ (ii) an outer hydrogen bond network involving the indole $\mathrm{N}-\mathrm{H}$ groups and the amide $\mathrm{C}=\mathrm{O}$ (see the green dotted lines in Fig. $1 \mathrm{a}$ and the red, green and blue colored strands in Fig. $1 \mathrm{~b}$ ). The $\mathrm{N} \cdots \mathrm{O}$ distance $(2.84(1) \AA)$ is consistent with that found for indole $\mathrm{N}$ $\mathrm{H}$ group of Trp residues involved in hydrogen bonding interactions in peptides and proteins. ${ }^{17 \mathrm{~b}}$ The $\mathrm{NH} \cdots \mathrm{O}$ angle of only $139(1)^{\circ}$ is likely due to the bifurcated nature of the hydrogen bond since the acceptor, the amide $C=O$, is already engaged in the inner hydrogen bond network. The two threefold hydrogen bonded helices, which adopt opposite handedness, are emphasized in Fig. 1b. Importantly, the additional interaction provided by the amino ester side chain allows each consecutive monomer inside the stacks to be maintained by six hydrogen bonds (Fig. 1a), compared to three in previously reported BTA structures, thus potentially strengthening the overall assembly (vide infra).

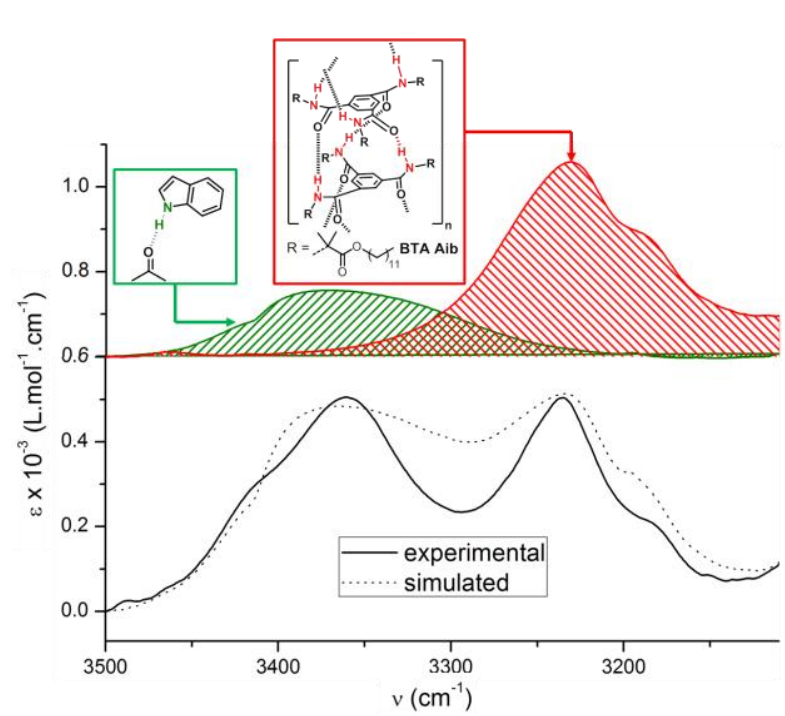

Fig. 2 FT-IR spectrum of (S)-BTA $\operatorname{Trp}^{\mathrm{C} 12}$ in $\mathrm{MCH}\left(10^{-2} \mathrm{~mol}^{-1} \mathrm{~L}^{-1}, 293 \mathrm{~K}\right)$, zoom on the N-H region (see the $\mathrm{C}=\mathrm{O}$ region in Fig. $\mathrm{S} 1 \mathrm{~b}$ ). The $\mathrm{FT}-\mathrm{IR}$ spectra of the models (indole in acetone, $5 \times 10^{-3} \mathrm{~mol} . \mathrm{L}^{-1}$, and BTA Aib in $\mathrm{MCH}, 10^{-2} \mathrm{~mol}^{-\mathrm{L}^{-1}}$ ) are shown with an offset of $600 \mathrm{~L} \cdot \mathrm{mol}^{-1} \cdot \mathrm{cm}^{-1}$. The simulated spectrum is obtained by addition of the FT-IR spectra of indole $(\times 3)$ and of BTA Aib.

A set of experiments has been carried out in order to probe whether this unusual type of helices with a double hydrogen bond network also exists in solution. (S)-BTA $\operatorname{Trp}^{\text {C12 }}$ has been selected for the solution studies given its good solubility in apolar solvents. Firstly, the FT-IR spectra of (S)-BTA $\operatorname{Trp}^{\text {C12 }}$ in methylcyclohexane $(\mathrm{MCH})$ and in solid state have been compared to that of solid (S)-BTA $\operatorname{Trp}^{i-\mathrm{Pr}}$. The three FT-IR spectra exhibit the same bands in the $\mathrm{N}-\mathrm{H}$ and $\mathrm{C}=\mathrm{O}$ regions which suggests that (S)-BTA $\operatorname{Trp}^{\mathrm{C12}}$ and (S)-BTA $\operatorname{Trp}^{i-\mathrm{Pr}}$ form the same type of self-assemblies (Fig. S1). Then, the nature of these bands have been definitively established by using BTA $\mathrm{Aib}^{11 \mathrm{e}}$ in $\mathrm{MCH}$ and indole in acetone as models of the inner and outer hydrogen bonding interactions, respectively, found in the structure of (S)-BTA $\operatorname{Trp}^{i-P r}$. Thus, the bands with absorption maxima at $v=3361 \mathrm{~cm}^{-1}$ and $v=3235 \mathrm{~cm}^{-1}$ correspond to indole $\mathrm{N}-\mathrm{H}$ and amide $\mathrm{N}-\mathrm{H}$ groups, respectively, both hydrogen bonded to amide $\mathrm{C}=\mathrm{O}$ (Fig. 2). As a matter of comparison, free indole and amide $\mathrm{N}-\mathrm{H}$ bands both exhibit maxima at ca. $v=3440 \mathrm{~cm}^{-1}$ (Fig. S2a). The simulated FT-IR spectrum, obtained by combining those of the models, resembles the experimental one except that the indole $\mathrm{N}-\mathrm{H}$ band is broader which is likely due to a less directional hydrogen bonding interaction for indole in acetone relatively to the same interaction taking place in the helical structure of (S)-BTA Trp ${ }^{\text {C12 }}$. The absorption maxima corresponding to ester band $\left(v=1742 \mathrm{~cm}^{-1}\right.$, free $)$ and amide $I$ band $\left(v=1633 \mathrm{~cm}^{-1}\right.$, bonded) are also consistent with (S)-BTA $\operatorname{Trp}^{\text {C12 }}$ adopting a similar hydrogen bond network in solution than (S)-BTA Trp ${ }^{i-P r}$ in the crystalline state (Fig. S2b).

The Small-Angle Neutron Scattering (SANS) analysis of (S)-BTA $\operatorname{Trp}^{\mathrm{C} 12}$ in $\mathrm{C}_{7} \mathrm{D}_{8}\left(4.4 \times 10^{-3} \mathrm{~mol}^{-\mathrm{L}^{-1}}\right)$ shows a $\mathrm{q}^{-1}$ dependency of the scattered intensity at low $q$ values which is characteristic of the presence of rigid one-dimensional objects (Fig. 3). $¥$ The data extracted from the fit indicate that these objects are very long cylinders $\left(L>1000 \AA, D P_{w}>275\right)$ with a radius of $12.9 \AA$ which is close to the one of the isolated molecule in its fully extended conformation (17 $\AA$ ). $\S$ This analysis thus 
Journal Name

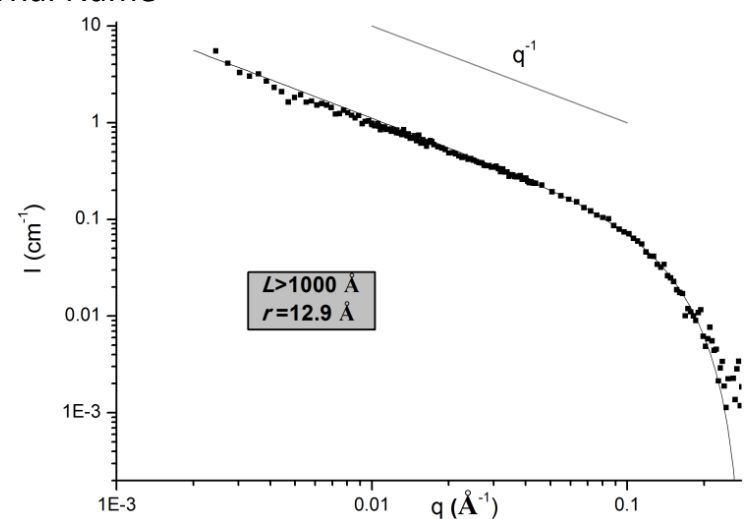

Fig. 3 SANS analysis (C) of (S)-BTA Trp ${ }^{\text {c12 }}$ in $C_{7} D_{8}\left(5.61{\mathrm{~g} . \mathrm{cm}^{-3}}^{-3} 4.4 \times 10^{-3} \mathrm{~mol}^{-1}, 293 \mathrm{~K}\right.$ ) The curve was fitted $(-)$ according the form factor for rigid rods of infinite length with a circular cross section and a uniform scattering length density ( $L=$ length, $r=$ radius).

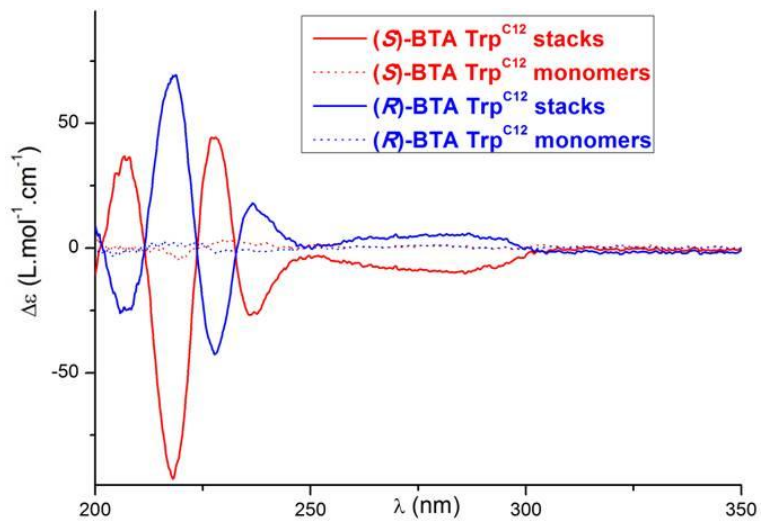

Fig. 4 CD spectra at $293 \mathrm{~K}$ of (S)-BTA $\operatorname{Trp}^{\mathrm{C} 12}\left(10^{-4} \mathrm{~mol}^{-L^{-1}}, \mathrm{MCH}\right.$, stacks), (S)-BTA $\operatorname{Trp}^{\mathrm{C} 12}$ $\left(10^{-3}\right.$ mol. $\mathrm{L}^{-1}, \mathrm{EtOH}$, monomers $),(\boldsymbol{R})$-BTA $\operatorname{Trp}^{\mathrm{C} 12}\left(10^{-4} \mathrm{~mol} . \mathrm{L}^{-1}, \mathrm{MCH}\right.$, stacks $)$ and $(\boldsymbol{R})$-BTA $\operatorname{Trp}^{\mathrm{C} 12}\left(10^{-3} \mathrm{~mol}^{-1} \mathrm{~L}^{-1}, \mathrm{EtOH}\right.$, monomers). For the corresponding UV-Vis absorption spectra see Fig. S4.

corroborates the presence in solution of supramolecular polymers with a single molecule of (S)-BTA $\operatorname{Trp}^{\text {C12 }}$ in the crosssection.

The chiral nature of the polymers formed by self-assembly of (S)-BTA $\operatorname{Trp}^{\mathrm{C12}}$ monomers was probed by Circular Dichroism (CD) spectroscopy $\left(10^{-4} \text { mol. } \mathrm{L}^{-1}, \mathrm{MCH} \text {, Fig. 4) }\right)^{\S \S}$ In contrast to monomers, assemblies of (S)-BTA Trp ${ }^{\text {c12 }}$ display a set of intense $C D$ signals with a negative Cotton effect centered at ca. $280 \mathrm{~nm}$ and two successive bisignated $C D$ signals $\left(\lambda^{-}=237\right.$ $\mathrm{nm} / \lambda^{+}=227 \mathrm{~nm}$ and $\left.\lambda^{-}=218 \mathrm{~nm} / \lambda^{+}=207 \mathrm{~nm}\right)$. The wellstructured and intense $C D$ band at $280 \mathrm{~nm}$ is related to the longer wavelength absorption maxima of the indole unit. $C D$ spectra of previously studied BTA assemblies usually display a single (broad) CD signal in the $200-250 \mathrm{~nm}$ region, as it is the case for the BTA derived from the dodecyl ester of LPhenylalanine (see the overlaid spectra in Fig. S5). ${ }^{11 \mathrm{c}}$ This corroborates that, in (S)-BTA $\operatorname{Trp}^{\text {C12 }}$ assemblies, the indole side chains are located in a well-defined chiral environment. As expected, (S)-BTA $\operatorname{Trp}^{\mathbf{C 1 2}}$ and (R)-BTA $\operatorname{Trp}^{\mathbf{C 1 2}}$ feature mirrorimage CD spectra reflecting the opposite handedness of their helical assemblies.

This full set of analyses (FT-IR, SANS and CD) demonstrates the ability of (S)-BTA Trp ${ }^{\text {C12 }}$ monomers to assemble into long, onedimensional helical stacks in solution similar to the ones reported for other BTA assemblies but with additional hydrogen bonding interactions involving the indole moieties of

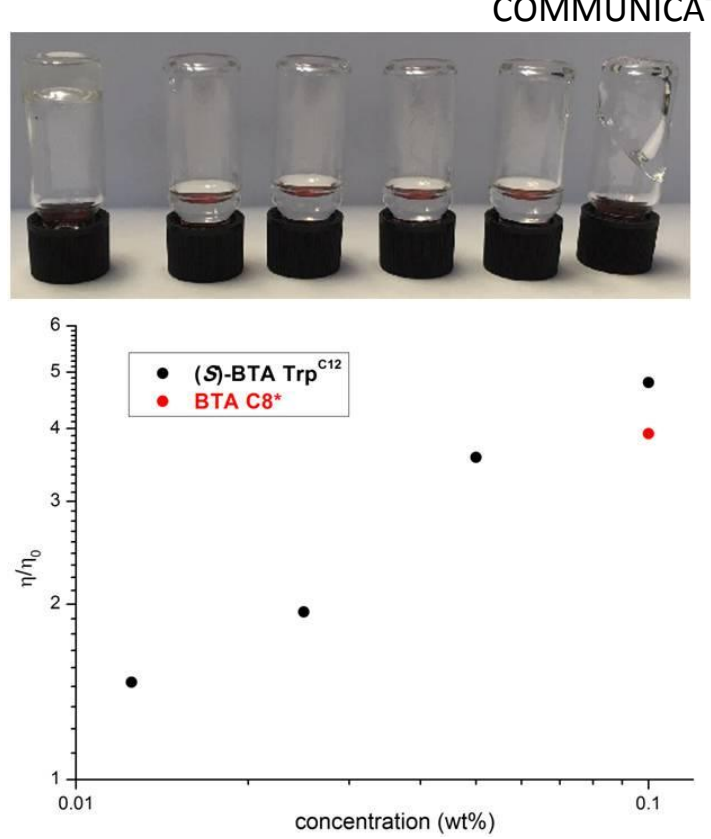

Fig. 5 Top: Pictures of $2 \times 10^{-2}$ mol. $L^{-1}$ toluene solutions of various ester and alkyl BTAs 2 minutes after inverting the vials. From left to right: (S)-BTA $\operatorname{Trp}^{\mathrm{C12}},(S)$-BTA ${ }^{\mathrm{NMe}} \operatorname{Trp},(S)$ BTA Met, BTA Aib, BTA C8 and BTA C8*. (S)-BTA Met: BTA derived from the dodecyl ester of L-methionine, BTA C8: BTA endowed with thee octyl side chains. BTA C8*: BTA endowed with two octyl side chains and one (S)-1-methylheptyl side chain. See Chart S1 for the chemical structures of these BTAs. Bottom: Relative viscosity of (S)-BTA $\operatorname{Trp}^{\mathrm{C} 12}$ and BTA C8* solutions in toluene versus concentration (293 K).

the side chain. FT-IR (Fig. S6) and CD (Fig. S7) analyses in $\mathrm{MCH}$ indicate that at room temperature the helical assemblies are identical over several order of magnitudes of concentrations $\left(2 \times 10^{-2} \mathrm{~mol}^{-1} \mathrm{~L}^{-1} 2.0 \times 10^{-6} \mathrm{~mol}^{-1} \mathrm{~L}^{-1}\right)$. Variable-temperature $\mathrm{CD}$ and UV-Vis analyses (Fig. S8) have then been performed to probe the thermal stability of the helical assemblies under very diluted conditions $\left(2.0 \times 10^{-6} \mathrm{~mol}^{-1} \mathrm{~L}^{-1}\right.$. The transition occurs between helical stacks (with a double hydrogen bond network) and monomers at a remarkably elevated temperature $(\approx 360$ K). ${ }^{18}$ It infers that these assemblies are more stable, by at least one order of magnitude, than those formed by the other ester BTA assemblies ${ }^{11 e}$ and are at least as stable as alkyl BTAs

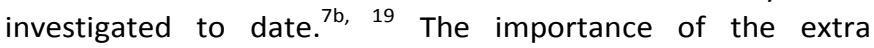
hydrogen bonds in stabilizing the helical assemblies of (S)-BTA Trp $^{\text {C12 }}$ is further supported by the fact that (S)-BTA ${ }^{\text {NMe }}$ Trp, which lacks the indole $\mathrm{N}-\mathrm{H}$ group, does not form long assemblies in $\mathrm{MCH}$ (Fig. S9).

Finally, we have examined whether the high stability of these helical assemblies, explained at the molecular scale by the six hydrogen bonds connecting adjacent BTA monomers within the stacks, translated into an improved property at the macromolecular level. With this aim in mind, we have prepared $2 \times 10^{-2}$ mol. $^{-1}$ toluene solutions of (S)-BTA Trp ${ }^{\text {C12 }}$, of (S)-BTA ${ }^{\text {NMe }}$ Trp and of a set of ester BTAs and alkyl BTAs previously-found to form helical assemblies in solution. From all of these samples, only (S)-BTA $\operatorname{Trp}^{\text {C12 }}$ forms a self-standing gel for more than 2 minutes after inverting the tube (Fig. 5 top). The solution of (S)-BTA $\operatorname{Trp}^{\text {C12 }}$ is notably more viscous than that of BTA C8*, an alkyl BTA with one optically pure 1methylheptyl chain. ${ }^{7 \mathrm{~b}}$ The solution containing (S)-BTA ${ }^{\mathrm{NMe}}$ Trp is fluid as anticipated for the presence of short species only. The high viscosity of (S)-BTA $\operatorname{Trp}^{\text {C12 }}$ was confirmed under more 


\section{COMMUNICATION}

diluted conditions $\left(7.9 \times 10^{-4} \mathrm{~mol}^{-1}\right.$, Fig.5 bottom $)$. The high viscosity of (S)-BTA $\operatorname{Trp}^{\text {C12 }}$ means that the overlap concentration is below $0.1 \mathrm{wt} \%$, which yields a lower estimate for degree of polymerization of the stacks: DPn>290 at a concentration of $0.1 \mathrm{wt} \%{ }^{20}$

In this study, we brought to light the ability of the peripheral indole $\mathrm{N}-\mathrm{H}$ groups to stabilize helical BTA assemblies through hydrogen bonding interactions with the amide $\mathrm{C}=\mathrm{O}$. Without these additional interactions, the presence of ester $\mathrm{C}=\mathrm{O}$ as a hydrogen bond acceptor would actually have destabilized the formation of supramolecular polymers under the same conditions. As a consequence of this extra stabilization, helical assemblies of BTA Trp are very long and remain stable at low concentrations and high temperatures. In BTA Trp, the supramolecular chirality is expressed at two levels, the inner and outer hydrogen bond networks, and this may offer the opportunity to amplify the chirality to a greater extent compared to classical BTAs. Studies towards this goal are underway in our laboratory as well as the implementation of these assemblies as scaffolds for asymmetric catalysis.

This work was supported by the Labex MiChem, part of French state funds managed by the Agence Nationale de la Recherche (ANR) within the Investissements d'Avenir programme under reference ANR-11-IDEX-0004-02, and by the ANR (project ANR-13-BS07-0021 SupraCatal). The GDR 3712 Chirafun is acknowledged for stimulating discussion. Jacques Jestin (LLB, Saclay) is acknowledged for assistance with SANS experiment.

\section{Conflicts of interest}

\section{There are no conflicts to declare.}

\section{Notes and references}

¥ (S)-BTA $\operatorname{Trp}^{\text {C12 }}$ adopts a similar supramolecular structure in toluene and $\mathrm{MCH}$ as indicated by the virtually identical FT-IR spectra obtained in these solvents (Fig. S3).

$\S$ As obtained by geometry optimization using molecular mechanic method (MM3) with the software Scigress (Fujitsu).

$\S \S(S)$-BTA Trp ${ }^{\text {c12 }}$ is fully assembled down to $2.0 \times 10^{-6}$ mol. $^{-1}$ at 293 $\mathrm{K}$ in $\mathrm{MCH}$ as demonstrated by FT-IR and CD analyses performed at various concentrations (Figs. S6 and S7, respectively).

1. (a) E. Yashima, N. Ousaka, D. Taura, K. Shimomura, T. Ikai and K. Maeda, Chem. Rev., 2016, 116, 13752; (b) M. Liu, L. Zhang and T. Wang, Chem. Rev., 2015, 115, 7304.

2. (a) S. Cantekin, T. F. A. de Greef and A. R. A. Palmans, Chem. Soc. Rev., 2012, 41, 6125; (b) Y. Dorca, J. Matern, G. Fernández and L. Sánchez, Isr. J. Chem., 2019, DOI: 10.1002/ijch.201900017.

3. (a) M. Raynal, F. Portier, P. W. N. M. van Leeuwen and L. Bouteiller, J. Am. Chem. Soc., 2013, 135, 17687; (b) E. Huerta, B. van Genabeek, B. A. G. Lamers, M. M. E. Koenigs, E. W. Meijer and A. R. A. Palmans, Chem. Eur. J., 2015, 21, 3682; (c) L. N. Neumann, M. B. Baker, C. M. A. Leenders, I. K. Voets, R. P. M. Lafleur, A. R. A. Palmans and E. W. Meijer, Org. Biomol. Chem., 2015, 13, 7711; (d) A. Desmarchelier, X. Caumes, M. Raynal, A. Vidal-Ferran, P. W. N. M. van Leeuwen and L. Bouteiller, J. Am. Chem. Soc., 2016, 138, 4908; (e) J. M. Zimbron, X. Caumes, Y. Li, C. M. Thomas, M. Raynal and L. Bouteiller, Angew. Chem. Int . Ed., 2017, 56, 14016; (f) L. Yan, X. Caumes, M. Raynal and L. Bouteiller, Chem. Commun., 2019, 55, 2162.

4. Z. C. Shen, T. Y. Wang, L. Shi, Z. Y. Tang and M. H. Liu, Chem. Sci., 2015, 6, 4267.

5. S. H. Jung, J. Jeon, H. Kim, J. Jaworski and J. H. Jung, J. Am. Chem. Soc., 2014, 136, 6446.
6. (a) M. P. Lightfoot, F. S. Mair, R. G. Pritchard and J. E. Warren, Chem. Commun., 1999, 1945; (b) D. Ranganathan, S. Kurur, R. Gilardi and I. L. Karle, Biopolymers, 2000, 54, 289; (c) A. Paikar, A. Pramanik and D. Haldar, RSC Advances, 2015, 5, 31845; (d) P. P. Bose, M. G. B. Drew, A. K. Das and A. Banerjee, Chem. Commun., 2006, 3196; (e) P. Jana, A. Paikar, S. Bera, S. K. Maity and D. Haldar, Org. Lett., 2014, 16, 38; (f) A. D. Lynes, C. S. Hawes, K. Byrne, W. Schmitt and T. Gunnlaugsson, Dalton Trans., 2018, 47, 5259.

7. (a) Y. Matsunaga, N. Miyajima, Y. Nakayasu, S. Sakai and M. Yonenaga, Bull. Chem. Soc. Jpn, 1988, 61, 207; (b) P. J. M. Stals, M. M. J. Smulders, R. Martín-Rapún, A. R. A. Palmans and E. W. Meijer, Chem. Eur. J., 2009, 15, 2071.

8. (a) Y. Yasuda, E. lishi, H. Inada and Y. Shirota, Chem. Lett., 1996, 575; (b) K. Hanabusa, C. Koto, M. Kimura, H. Shirai and A. Kakehi, Chem. Lett., 1997, 429.

9. L. Brunsveld, A. P. H. J. Schenning, M. A. C. Broeren, H. M. Janssen, J. A. J. M. Vekemans and E. W. Meijer, Chem. Lett., 2000, 292.

10. T. F. A. de Greef, M. M. L. Nieuwenhuizen, P. J. M. Stals, C. F. C. Fitie, A. R. A. Palmans, R. P. Sijbesma and E. W. Meijer, Chem. Commun., 2008, 4306.

11. (a) M. de Loos, J. H. van Esch, R. M. Kellogg and B. L. Feringa, Tetrahedron, 2007, 63, 7285; (b) M. A. J. Veld, D. Haveman, A. R. A. Palmans and E. W. Meijer, Soft Matter, 2011, 7, 524; (c) A. Desmarchelier, M. Raynal, P. Brocorens, N. Vanthuyne and L. Bouteiller, Chem. Commun., 2015, 51, 7397; (d) X. Caumes, A. Baldi, G. Gontard, P. Brocorens, R. Lazzaroni, N. Vanthuyne, C. Troufflard, M. Raynal and L. Bouteiller, Chem. Commun., 2016, 52, 13369; (e) A. Desmarchelier, B. G. Alvarenga, X. Caumes, L. Dubreucq, C. Troufflard, M. Tessier, N. Vanthuyne, J. Idé, T. Maistriaux, D. Beljonne, P. Brocorens, R. Lazzaroni, M. Raynal and L. Bouteiller, Soft Matter, 2016, 12, 7824; (f) K. K. Bejagam, R. C. Remsing, M. L. Klein and S. Balasubramanian, Phys. Chem. Chem. Phys., 2017, 19, 258.

12. (a) J. Garner and M. M. Harding, Org. Biomol. Chem., 2007, 5, 3577; (b) L. K. Henchey, A. L. Jochim and P. S. Arora, Curr. Opin. Chem. Biol., 2008, 12, 692.

13. (a) F. W. Kotch, I. A. Guzei and R. T. Raines, J. Am. Chem. Soc., 2008, 130, 2952; (b) N. B. Hentzen, L. E. J. Smeenk, J. Witek, S. Riniker and H. Wennemers, J. Am. Chem. Soc., 2017, 139, 12815.

14. E. Schwartz, M. Koepf, H. J. Kitto, R. J. M. Nolte and A. E. Rowan, Polym. Chem., 2011, 2, 33.

15. R. Nomura, J. Tabei and T. Masuda, J. Am. Chem. Soc., 2001, 123, 8430 .

16. For covalent fixation of helical BTA assemblies see: (a) $M$. Masuda, P. Jonkheijm, R. P. Sijbesma and E. W. Meijer, J. Am. Chem. Soc., 2003, 125, 15935; (b) A. J. Wilson, M. Masuda, R. P. Sijbesma and E. W. Meijer, Angew. Chem. Int . Ed., 2005, 44, 2275.

17. (a) A. G. Cochran, N. J. Skelton and M. A. Starovasnik, Proc. Nat. Acad. Sci. USA, 2001, 98, 5578; (b) R. Mahalakshmi, A. Sengupta, S. Raghothama, N. Shamala and P. Balaram, J. Pept. Res., 2005, 66, 277; (c) A. Sengupta, R. Mahalakshmi, N. Shamala and P. Balaram, J. Pept. Res., 2005, 65, 113; (d) B. Adhikari, A. J. Lough, B. Barker, A. Shah, C. L. Xiang and H. B. Kraatz, Organometallics, 2014, 33, 4873; (e) N. Falcone, S. Basak, B. Dong, J. Syed, A. Ferranco, A. Lough, Z. She and H. B. Kraatz, Chempluschem, 2017, 82, 1282.

18. In this highly diluted condition, the error bar in the measurement of the ellipticity ( $<5 \mathrm{mdeg}$ ) is too high to allow precise recording of the $C D$ value as a function of the temperature.

19. (a) M. M. J. Smulders, A. P. H. J. Schenning and E. W. Meijer, J. Am. Chem. Soc., 2008, 130, 606; (b) Y. Nakano, T. Hirose, P. J. M. Stals, E. W. Meijer and A. R. A. Palmans, Chem. Sci., 2012, 3, 148.

20. M. Bellot and L. Bouteiller, Langmuir, 2008, 24, 14176. 